Elsevier required licence: (C2017. This manuscript version is made available under the CC-BY-NC-ND 4.0 license http://creativecommons.org/licenses/by-nc-nd/4.0/ 


\title{
Energy price, regulatory price distortion and economic growth: A case study of China
}

\author{
Xunpeng SHI ${ }^{\mathrm{a}, \mathrm{b}}$, Sizhong SUN ${ }^{\mathrm{c}}$ \\ a. Australia-China Relations Institute, University of Technology Sydney, \\ 15 Broadway Ultimo NSW 2007, Australia; \\ b. Energy Studies Institute, National University of Singapore, 29 Heng \\ Mui Keng Terrace, \#10-01, Bld A, Singapore 119620, Singapore. Email: \\ Xunpeng.shi@gmail.com \\ c. College of Business Law and Governance, James Cook University, \\ Townsville, QLD 4811, Australia. Email: Sizhong.Sun@jcu.edu.au
}

\begin{abstract}
:
Energy prices are often distorted by government control, which is usually justified on the grounds that such control will help mitigate the negative impact of price volatility from oil imports, and thus positively affect the domestic economy. In this paper, we show in a two-sector growth model, that regulatory price distortion can negatively affect the economy, and then, based on the model, we empirically estimate the impact of the price distortion on output growth in China, using monthly, time series data from 2005M1 to 2012M12. In contrast to the usual argument for regulatory control to mitigate price volatility, we find that regulatory price distortion negatively affects output growth in China during both the short and long term, because it is robust to different measures of output and price distortion. Hence, the argument that using price regulation to protect economic growth is undermined, and subsequently, this study lends its support to energy price deregulation. A market oriented, energy price regime may improve the resilience of the domestic economy to global, oil price shocks.
\end{abstract}

Key words: oil price; regulatory price; volatility; economic growth; China

JEL classification: C2, C6, E2, Q3 


\section{Introduction}

Policy makers generally believe that oil price shocks exert negative impacts on the domestic economy, and, due to this belief, price regulation in the energy market, such as price capping and subsidies, has been practiced for a long time and is still prevalent in many countries (IEA, 2015). Many policy makers prefer to maintain price regulations on the grounds that these measures can insulate the domestic economy from the negative impacts of high oil prices in the world market. For example, Brunei, and in the past, Indonesia and Malaysia, fixed their petroleum prices at a very low level (Wu et al., 2012).

Examining the impact of price distortion will have significant implications for policy makers. The consequences of price distortion due to energy price regulation may be beyond policy makers' expectations. Although policy makers hope such price regulation may help the domestic economy by reducing volatility, the induced distortion may actually exert negative impacts. If it can be demonstrated that the hypothesis that energy price distortion resulting from regulations to reduce international price volatility dampens a domestic economy, then the basis for maintaining price regulation will be undermined.

Despite its policy significance, to the best of our knowledge no previous study demonstrates how regulatory energy price distortion affects the relationship between international oil price and national economic development. Previous literature focuses on two distinct aspects of the relationship. On the one hand, debate focuses on the relationship between the international oil price and national economy without examining intermediate 
price regulation. The relationship between oil price shock, or volatility, and the macroeconomy has been debated since the early 1980s (Hamilton, 1983) when the first oil crisis occurred and global recessions followed (Jones et al., 2004; Segal, 2007). These studies were initially spurred on by the stagnation of the US economy in the 1970s, as oil price shocks were thought to be the only promising hypothesis that explained the stagflation (Barsky and Kilian, 2004). The issue of oil price shock revitalized in the 2000s with the fact that, between 2001 and 2008, the oil price rose more than 600\% while in contrast, average quarterly core inflation in the US was only about $2 \%$ over the same period (Clark and Terry, 2009). More recent studies examine details of oil price shock on the macroeconomy relationship. For example, An et al. (2014) found that the relationship between higher and lower oil prices is asymmetric while Cunado et al. (2015) found this relationship may be different in different countries. Studies also extended from examining economic growth to stocks, household expenditure, etc. (Broadstock et al., 2014; Zhang et al., 2014) and to examining more complicated relationships (Zhang, 2008). In the Chinese case, the focus of this paper, previous studies (Ju et al., 2014; Ou et al., 2012; Tang et al., 2010; Zaouali, 2007) generally find a negative impact on economic growth. There is also a detailed study on how the oil price shocks affects consumption in China (Zhang et al., 2014).

On the other hand, there are numerous studies examining the relationship between subsidies and energy consumption, or emissions, or economic growth, without considering how price movement affects the outcome. For example, IEA (1999) found that the removal of energy subsidies would reduce energy 
consumption and $\mathrm{CO} 2$ emissions in eight non-OECD countries. The IMF (2013) concluded that distorted energy prices will distort resource allocation to less productive usage, causing wasteful consumption. Wasteful consumption, as a result of fuel subsidies, was observed in the Nigerian case (Nwachukwu and Chike, 2011). A Chinese case study concludes that energy price distortions impede the improvement of energy consumption structures (Liu and Li, 2011). He et al. (2014) proved that competitive, electricity market prices could achieve energy savings and simultaneously, have a positive impact on social welfare. Studies on the macroeconomic impact of energy subsidies often use CGE models and demonstrate that subsidies have a negative impact on economic growth, employment, and social welfare (Bhattacharya and Kojima, 2010; Wu et al., 2012).

To fill this gap, this paper intends to revisit the impact of oil prices on economic development giving consideration to domestic price distortion due to regulation, both theoretically, through a two-sector growth model, and empirically, using a time-series analysis of China's situation ${ }^{1}$. This paper focuses on China, a large, developing economy. On the one hand, China's fast economic growth creates a huge demand for resources such as oil, while on the other hand it also maintains a number of intervention measures, such as price control and manipulated fuel tax, in the domestic liquid fuel (hereafter fuel) market. Since 2009, imported oil has accounted for more than half of total oil consumption in China, and at the same time the oil price has become

\footnotetext{
${ }^{1}$ Note that oil price regulations have different effects on the economy, depending on whether the country is an oil importing or exporting economy and whether price regulations are imposed on oil consumption or production. In this paper, we focus on the oil importing country (China) and the price regulations are imposed on oil consumption.
} 
more volatile. Investigating the impact of price distortion, which occurs due to intervention measures, will lead to significant implications for policy makers, not only in China, but also in other developing economies that regulate the energy price. Later, our empirical exercise will reveal that such distortion can do harm to the industrial output. Another feature of this study will combine the theoretical modelling with empirical analysis, where the theoretical modelling provides guidance for the empirical exercise, and the empirical exercise is implemented using a widely used technique, the Autoregressive Distributed Lag Model (ARDL).

The contribution of this paper is three fold. First, we innovatively introduce the role of fuel price distortion into the well-examined, oil price shock, macroeconomy nexus. We argue that market distortion will have a significant negative impact on the relationship. Second, we illustrate the impact of price distortion in a two-sector growth model. Our two-sector model is consistent with a recent study that calls for structural models, including the oil market, to be used to disentangle cause and effect in the relationship between oil prices and the economy (Kilian, 2014). Third, we propose a novel measurement of the price distortion. The price distortion is measured as relative differences between average gasoline prices in China and the New York Harbor, conventional gasoline, regular spot price. In contract, previous studies, such as Lin \& Jiang (2011), use the US gasoline retailing price as a reference, which suffers from tax distortions. Fourth, our empirical exercise focuses on China, a large, fast growing, developing economy with high dependence on imported oil and price distortion, which leads to significant 
implications for policy makers both in China, and other developing countries.

The rest of the paper proceeds as follows. Following the introduction, in Section 2 we present a discussion of oil consumption and the energy pricing mechanism in China, providing background information for the subsequent exercise, and we explain the method of measuring price distortion in China. Section 3 presents a two-sector growth model, where we illustrate that oil price distortion indeed affects the domestic economy. Using implications from the theoretical model in Section 3, we then empirically test the impact of price distortion in China in Section 4. Section 5 concludes the paper with policy implications.

\section{Fuel pricing mechanism and price distortion in China}

Due to its escalating volume of oil consumption, increasing dependence on oil imports, and gradually liberalizing, domestic, oil pricing mechanism, researchers have expected a more active interaction between the world oil price and China’s macro-economy (Du et al., 2010; Wu et al., 2013). Therefore, not surprisingly, China is a good case to study the role of market distortion and oil price shocks. In this section, we will discuss the pricing mechanisms in the energy market, and measure the associated price distortion.

\subsection{The oil consumption and pricing mechanisms}

China's energy consumption, as well as its dependence on imported oil, has been increasing dramatically in the past two decades and is expected to continuously grow into the future (IEA, 2015). From 1990 to 2013, China's GDP grew at an annual rate of $9.9 \%$ on average, and is expected to grow at an 
annual average rate of 4.8\% during the period 2013 to 2040 (IEA, 2015). Such fast economic growth leads to strong demand for energy. In 2009, China became the world's largest energy consumer.

Meanwhile, China has successfully adopted a gradual approach to removing subsidies (Lin and Jiang, 2011). Before 1998, energy prices were heavily regulated, and often under-priced, due to the notion that energy is critical to economic growth and social development (Ouyang and Sun, 2015). In the 1980s and 1990s, China adopted a dual-track pricing system, under which prices for most oil products were tightly regulated, while the rest were traded in the market, more or less freely. A market-based petroleum pricing mechanism was adopted in 1998 and in October 2001, oil product prices were linked to major international futures markets (Du et al., 2010). They were first benchmarked against the Singapore futures market, and later, in 2001, the benchmark was extended to Singapore, Rotterdam and New York futures markets, where an unpublished weight was used in setting domestic prices (Du et al., 2010). In 2006, this price benchmark was changed from refinery product prices to the Brent, Dubai, and Minas crude oil prices. This price benchmarking, while it enables domestic markets to follow international markets, is also intended to insulate domestic markets from the volatility of petroleum prices in the global markets (IEA, 2010). Due to this intention, even with those liberalizing reforms implemented in early 2000, the pricing regime was plagued by ad hoc subsidies and non-transparent, inconsistently enforced, pricing behaviours.

In 2009, China introduced a formula based, pricing mechanism for oil 
products. According to this formula, domestic fuel prices may be adjusted when international, crude oil prices, measured as a weighted average of the Brent, Dubai and Cinta crude oil prices, change by more than $4 \%$ over a period of 22 working days (Government of China, 2008).

This pricing mechanism tends to smooth the price volatility in the fuel markets. When the average crude oil price is below US\$80 a barrel, domestic gasoline prices move relatively freely; between US\$80 and US\$130 a barrel, domestic prices are responsive, but cannot increase as much as the crude oil price does; and above US\$130, fuel tax breaks will be used to keep domestic prices low. Furthermore, fuel price adjustments have lagged behind the world price movement (Kojima, 2012). Distributors and consumers take advantage of this lag in fuel price adjustments by hoarding oil products when international oil prices register large rises and selling them after the price adjustments (China.org.cn, 2013).

With the mounting demand for full marketization of prices of domestic oil products, China again changed its oil pricing mechanism in March 2013. It may adjust domestic oil prices every 10 working days regardless of how much international oil prices change, unless price changes in international oil markets are not more than 50 yuan per ton. The government retains the power to suspend, postpone or downsize the price adjustment in special cases, such as sharp rises in domestic inflation, emergencies or dramatic swings in global oil prices. However, there are no pre-defined conditions under which the government will intervene and thus the government may surprise the market. For example, in the short period between 28 November, 2014 and 12 January, 
2015, the Chinese government raised the fuel tax three times to take advantage of the declining international oil price (Huang, 2015). The National Development and Reform Commission (NDRC) claims that the new mechanism is more responsive to global oil market changes, and will help the country better utilize overseas resources to ensure domestic oil supplies (China.org.cn, 2013).

\subsection{Measurement of fuel price distortions}

Even though China is gradually liberalizing the pricing mechanism of domestic oil products, as discussed above, there still exists significant price control in the energy market. Such price control creates distortions in the energy market. We measure the price distortion in the following way:

First, we calculate the average monthly gasoline price (Chinese yuan per ton) in China over three types of gasoline without lead (namely gasoline no. 90, 93, and 97), where the prices for these three types of gasoline are sourced from the CEIC database. Second, we extract the New York Harbor, conventional gasoline, regular spot price, which is sourced from the US Energy Information Administration (EIA) and is free from tax distortion. The unit of this price is US dollars per gallon, which we then convert into US dollars per ton using the formula 1 gallon of gasoline $=2.7974 \mathrm{~kg}$. This price is further converted into Chinese currency (yuan) using the period average of official, nominal exchange rates sourced from the IMF.

Third, after converting the China and US gasoline prices to the same unit (Chinese yuan per ton), we construct measures of domestic, oil price distortion. Starting from a ratio of China price against US price, namely $\sigma=$ 
$P_{\text {China }} / P_{U S}$, the main measure of price distortion is $\tilde{\sigma}=|\sigma-1|$, where $P$ denotes price and $\tilde{\sigma}$ represents price distortion. In order to allow for an asymmetric impact of price distortion in our exercises later, we also construct measures of upward and downward price distortions, as $\tilde{\sigma}^{+}=\max \{\sigma-1,0\}$ and $\tilde{\sigma}^{-}=\max \{1-\sigma, 0\}$ respectively. Note that measures of price distortion are functions of $\sigma$, which will be used in our subsequent model derivation. One may argue that the measures of price distortion are driven primarily by transportation costs. However, given the fixed geographical distance between China and the US, transportation costs exhibit little variation, and hence $d \tilde{\sigma}$ ( $d \tilde{\sigma}^{+}$and $d \tilde{\sigma}^{-}$) captures the change of price distortion in China, relative to the US.

Figure 1 presents the constructed price distortion. We can observe that there exist significant price distortions in China. On average, China's price is around $46.15 \%$ higher than that of the US. In addition, even though China is trying to liberalize its oil product pricing mechanism, the distortion does not appear to be reducing. In addition, there appears to be a structural break in 2009M1. After 2009M1, the average price distortion is clearly higher than that of before 2009M1. Before 2009M1, China’s price is, on average, only 26.1\% higher than that of the US, while in contrast it is, on average, $66.19 \%$ higher after 2009M1. One reason for the increase in the gasoline price is that fuel tax was increased from $0.2 \mathrm{CNY}$ (US\$0.3 cents) per litre to $1 \mathrm{CNY}$ (US $\$ 0.15$ cents) per litre from 2009. Given the continuous, high level in the oil price, it is argued that even the gasoline was under-priced (Xin Jing Bao, 2011).

$<$ Figure 1 about here $>$ 


\section{The model}

Price controls are the main reason for price distortion in the energy market. Nevertheless, they are often justified on the grounds that they shield a domestic economy from undesired, oil price shocks in the world market. Such oil price shocks can lead to inflation and recession in a domestic economy (Barsky and Kilian, 2004; Darby, 1982). This negative impact, however, is questioned in later studies (Bernanke et al., 1997). A number of recent studies suggest that the negative impact does not derive from the oil price shocks themselves, instead, they suggest it is from policy response to the oil price shocks (Kilian, 2008).

In addition, price controls, such as subsidies or taxes, themselves negatively affect a domestic economy. A number of studies show that energy price distortion hurts economic growth (Tang et al., 2010; Wu et al., 2013). Conceptually, regulated energy prices can affect a domestic economy in the following three ways: (i) subsidies, or surrendered profits from state owned oil companies, transfer government revenue to consumers in a way that is not necessarily efficient. Not surprisingly, we can expect welfare loss from such subsidies; (ii) the price distortion, due to either subsidy or tax, leads to inefficient allocation of energy among industrial users. Empirically, Linn (2008), shows that firms respond to energy price change; (iii) for retail consumers, the low (high) energy price can also lead to inefficient consumption of energy (GSI,2011). For example, faced with cheaper fuel prices, consumers are more likely to use vehicles more intensively, and have less incentive to switch to higher energy efficient vehicles. 
Therefore, we expect price distortion to affect the domestic economy. Next we explore the impacts of fuel price distortion, measured as the price deviation between domestic and world markets, on the domestic economy in a twosector growth model. In the model, we show that price distortion affects steady state output in an asymmetric manner.

\subsection{A two sector growth model}

With an endowment of labour $L$, the economy consists of two sectors, namely the oil sector and the final goods sector. A representative consumer chooses a sequence of consumption of final goods to maximize their life time utility, as follows:

$$
\max _{\left\{c_{t}\right\}} U=\sum_{t=0}^{\infty} \rho^{t} \ln \left(c_{t}\right)
$$

where $t$ denotes time, $\rho$ is the discount rate and $c$ denotes quantity of consumption. At each period, the consumer is faced with the following budget constraint:

$$
c_{t}+k_{t+1}=w_{t}+r_{t} k_{t}+(1-\delta) k_{t}
$$

where $k$ denotes capital they own, $w$ is their wage income, and $r$ and $\delta$ are rental and depreciation rates of capital respectively. Solving the utility maximization problem, we obtain an Euler equation as follows:

$$
\frac{c_{t+1}}{\rho c_{t}}=r_{t+1}+1-\delta
$$

In the final goods sector, capital, labour, and oil are used to produce final goods in a constant return to scale Cobb-Douglas function:

$$
Y_{t}=A L_{t}^{1-\alpha-\beta} K_{y t}^{\alpha} O_{t}^{\beta}
$$

where $Y, A, L, K_{y}$, and $O$ denote the output, technology, labour, capital used in 
the final goods sector, and oil inputs respectively, and $\alpha$ and $\beta$ are two parameters where $\alpha \in(0,1), \beta \in(0,1), \alpha+\beta \in(0,1)$. The oil inputs are sourced from either domestic or world markets. Let $p_{t}$ denote the oil price in the world market and $\sigma_{t} p_{t}$ denote domestic oil price. If there is no distortion in the market, we shall observe $\sigma_{t}$ to be one, due to the law of one price. Hence $\sigma_{t}$ contains information on the distortion in the domestic oil market, assuming that the world market is distortion free. As discussed in the previous section, from $\sigma_{t}$, one can construct a simple index to measure the distortion in domestic market as $\tilde{\sigma}_{t}$, where the higher value of the index implies a higher level of distortion. Note that $\frac{d \sigma_{t}}{d \widetilde{\sigma}_{t}}=\left\{\begin{array}{c}1, \text { if upward distortion } \\ -1, \text { if downward distortion }\end{array}\right.$. Besides, as our aim is to examine the impact of such distortion on domestic economy, we take $\sigma_{t}$ as exogenous, rather than explicitly modelling the formation of $\sigma_{t}$.

Firms in the final goods sector choose employment of labour, capital, and oil to maximize their profits:

$$
\max _{\left\{L_{t}, K_{y t}, O_{t}\right\}} Y_{t}-w_{t} L_{t}-r_{t} K_{y t}-\gamma_{t} O_{t} \sigma_{t} p_{t}-\left(1-\gamma_{t}\right) O_{t} p_{t}
$$

where $1-\gamma$ denotes oil dependence, namely the share of oil consumption that is sourced from the world market. Profit maximization yields the following first order conditions:

$$
\begin{aligned}
& w_{t}=(1-\alpha-\beta) A L_{t}^{-\alpha-\beta} K_{y t}^{\alpha} O_{t}^{\beta} \\
& r_{t}=\alpha A L_{t}^{1-\alpha-\beta} K_{y t}^{\alpha-1} O_{t}^{\beta} \\
& \beta A L_{t}^{1-\alpha-\beta} K_{y t}^{\alpha} O_{t}^{\beta-1}-\left(\gamma_{t} \sigma_{t}+1-\gamma_{t}\right) p_{t}=0
\end{aligned}
$$

Equation (5) defines the demand for oil, from which we can derive the corresponding demand for domestic oil as: 


$$
\gamma_{t} O_{t}=\gamma_{t}\left[\frac{\beta A L_{t}^{1-\alpha-\beta} K_{y t}^{\alpha}}{\left(\gamma_{t} \sigma_{t}+1-\gamma_{t}\right) p_{t}}\right]^{1 /(1-\beta)}
$$

In the oil sector, firms are engaged in two activities; oil extraction and discovering new oil reserves. The oil extraction is a Cobb-Douglas production function, as follows:

$$
X_{t}=S_{t} K_{x 1 t}^{\eta}
$$

where $X, S$, and $K_{x 1}$ denote the oil output, oil reserve, and capital used in the oil sector $\left(K_{x 1 t} \in[0,1]\right)$, and $\eta$ is the parameter that takes a value between zero and one to capture a diminishing return of capital investment in oil extraction. To discover a new oil reserve, firms need to invest capital, which is also subject to a diminishing return and takes a Cobb-Douglas functional form as follows:

$$
D_{t}=\mathrm{B} K_{x 2 t}^{\theta}
$$

where $D_{t}$ denotes the discovery of new oil in each period; $K_{x 2 t}$ is the capital stock committed to discovering a new oil reserve; $B$ denotes the productivity in discovering a new oil reserve; and $\theta \in(0,1)$. The economy is initially endowed with an oil reserve of $S_{0}$, and subsequently the oil reserve evolves in the following manner:

$$
S_{t+1}=S_{t}\left(1-K_{x t}^{\eta}\right)+\mathrm{D}_{\mathrm{t}}=S_{t}\left(1-K_{x t}^{\eta}\right)+\mathrm{B} K_{x 2 t}^{\theta}
$$

Subject to the transition of state variable $S$ (Equation 9), firms in the oil sector choose the level of capital to maximize their life time profits, with the Bellman equation as follows:

$$
\begin{aligned}
V\left(S_{t}\right)=\max _{\left\{K_{x 1 t}, K_{x 2 t}\right\}}\left\{X_{t} \sigma_{t} p_{t}-r_{t} K_{x 1 t}-r_{t} K_{x 2 t}+\rho V\left(S_{t+1}\right)\right\} \\
\quad=\max _{\left\{K_{x 1 t}, K_{x 2 t}\right\}}\left\{M_{t} S_{t}^{\beta} K_{x 1 t}^{\beta \eta}-r_{t} K_{x 1 t}-r_{t} K_{x 2 t}+\rho V\left(S_{t+1}\right)\right\}
\end{aligned}
$$


where $V()$ denotes the value function and $M_{t} \equiv \frac{\beta A L_{t}^{1-\alpha-\beta} K_{y t}^{\alpha} \gamma_{t}^{1-\beta} \sigma_{t}}{\gamma_{t} \sigma_{t}+1-\gamma_{t}}$. The second equation is obtained by plugging in the demand for domestic oil (Equation 6) and oil production function (Equation 7) into the first equation.

By differentiating the value function with respect to $K_{x 1 t}$ and $K_{x 2 t}$, we obtain the first order conditions as follows:

$$
\begin{gathered}
\beta \eta M_{t} S_{t}^{\beta} K_{x 1 t}^{\beta \eta-1}-r_{t}-\rho \eta S_{t} K_{x 1 t}^{\eta-1} \frac{\partial V}{\partial S_{t+1}}=0 \\
-r_{t}+\rho \theta B K_{x 2 t}^{\theta-1} \frac{\partial V}{\partial S_{t+1}}=0
\end{gathered}
$$

from which we can obtain the following equation:

$$
\frac{\beta \eta M_{t} S_{t}^{\beta} K_{x 1 t}^{\beta \eta-1}-r_{t}}{\eta S_{t} K_{x 1 t}^{\eta-1}}=\frac{r_{t}}{\theta B K_{x 2 t}^{\theta-1}}
$$

Using the Envelope Theorem, we can obtain $\frac{\partial V}{\partial S_{t}}=\beta M_{t} S_{t}^{\beta-1} K_{x 1 t}^{(\beta-1) \eta}-$ $\frac{r_{t}\left(1-K_{x 1 t}^{\eta}\right)}{\eta S_{t} K_{x 1 t}^{\eta-1}}$, which is then shifted one period forward (namely, $\frac{\partial V}{\partial S_{t+1}}=$ $\left.\beta M_{t+1} S_{t+1}^{\beta-1} K_{x 1 t+1}^{(\beta-1) \eta}-\frac{r_{t+1}\left(1-K_{x 1 t+1}^{\eta}\right)}{\eta S_{t+1} K_{x 1 t+1}^{\eta-1}}\right)$ and plugged into the above first order condition to obtain the following equations:

$$
\begin{aligned}
& \beta \eta M_{t} S_{t}^{\beta} K_{x 1 t}^{\beta \eta-1}=r_{t}+\rho \eta S_{t} K_{x 1 t}^{\eta-1}\left[\beta M_{t+1} S_{t+1}^{\beta-1} K_{x 1 t+1}^{(\beta-1) \eta}-\right. \\
& \left.\frac{r_{t+1}\left(1-K_{x 1 t+1}^{\eta}\right)}{\eta S_{t+1} K_{x 1 t+1}^{\eta-1}}\right] \\
& r_{t}=\rho \theta B K_{x 2 t}^{\theta-1}\left[\beta M_{t+1} S_{t+1}^{\beta-1} K_{x 1 t+1}^{(\beta-1) \eta}-\frac{r_{t+1}\left(1-K_{x 1 t+1}^{\eta}\right)}{\eta S_{t+1} K_{x 1 t+1}^{\eta-1}}\right]
\end{aligned}
$$

They characterize the optimal level of capital in the oil sector. Equation (11) indicates that the optimal level of capital invested in oil extraction shall be such that its marginal revenue (the right hand side of Equation 11) is equal to 
marginal cost (the left hand side of Equation 11). Note that since current oil extraction affects future oil extraction through the reduction of oil reserves, the marginal cost is the rental rate plus a term that accounts for the cost of reduction in oil reserves. Similarly, Equation 12 suggests that the capital shall be allocated to oil discovery such that its marginal cost (the rental rate) is equal to its marginal benefit (the right hand side of Equation 12).

The resource constraint in the economy (goods market clears) implies that:

$$
\begin{aligned}
& \quad C_{t}+K_{y t+1}-(1-\delta) K_{y t}+K_{x 1 t+1}-(1-\delta) K_{x 1 t}+K_{x 2 t+1}- \\
& (1-\delta) K_{x 2 t}+\left(1-\gamma_{t}\right) O_{t} p_{t}=Y_{t}
\end{aligned}
$$

where $C_{t}=L c_{t}$ and $K_{x 1 t}+K_{x 2 t}+K_{y t}=L k_{t}$. A competitive equilibrium in the

economy is then characterized by $\left\{C_{t}, K_{y t}, K_{x 1 t}, K_{x 2 t}, w_{t}, r_{t}, \gamma_{t}\right\}_{t=0}^{\infty}$ such that Equations (1), (3), (4), (9), (10), (11), (12), and (13) are satisfied.

\subsection{Impact of price distortion ( $\sigma$ ) at steady state}

We now focus on a steady state where consumption, output, capital stocks in the final goods sector, oil extraction and oil discovery, oil self-sufficiency, and domestic oil price distortion are constant, namely $C_{t}=C, Y_{t}=Y, K_{y \mathrm{t}}=K_{y}$, $K_{x 1 \mathrm{t}}=K_{x 1}, K_{x 2}=K_{x 2}, \gamma_{t}=\gamma$, and $\sigma_{t}=\sigma$. Since $C_{t}=C$, from Equation (1), the equilibrium interest rate in the steady state is constant, as follows:

$$
r=\frac{1}{\rho}+\delta-1
$$

From Equations (2) and (4), we can obtain:

$$
r=\alpha A L^{1-\alpha-\beta} K_{y}^{\alpha-1} O^{\beta}
$$

From Equation (9), we can solve for the steady state oil reserve as a function 
of capital stocks in oil extraction and oil discovery, as follows:

$$
S=\frac{B K_{x 2}^{\theta}}{K_{x 1}^{\eta}}
$$

We then re-write Equations (10), (11), and (12) as follows:

$$
\begin{aligned}
& \theta B K_{x 2}^{\theta-1}=\frac{(1-\rho) \eta S K_{x 1}^{\eta-1}}{K_{x 1}^{\eta}-1+\rho} \\
& r=(1-\rho) \beta \eta M S^{\beta} K_{x 1}^{\beta \eta-1} \\
& \frac{\eta}{\rho \theta B}=\frac{(2-\rho) K_{x 1}^{\eta}+\rho-1}{(1-\rho) S K_{x 1}^{\eta-1}} K_{x 2}^{\theta-1}
\end{aligned}
$$

Therefore, Equations (16), (17), and (19) are three equations with three unknowns (capital stocks in oil extraction and oil discovery, and steady state oil reserves). Solving these equations, we can obtain the following steady state capital stocks, oil reserve, and oil demand:

$$
\left\{\begin{array}{c}
K_{x 1}=1 \\
K_{x 2}=\frac{\rho \theta}{(1-\rho) \eta} \\
S=\frac{B \rho^{\theta} \theta^{\theta}}{(1-\rho)^{\theta} \eta^{\theta}} \\
O=\frac{B \rho^{\theta} \theta^{\theta}}{(1-\rho)^{\theta} \eta^{\theta} \gamma}
\end{array}\right.
$$

where the steady state is obtained by using the fact that $\gamma O=X=S$ in the steady state. Equation (20) suggests that the price ratio $(\sigma)$ does not affect the oil sector (oil extraction and discovery) in the steady state.

By plugging Equation (20) into Equations (15) and (18), we can obtain the following equation system:

$$
\left\{\begin{array}{c}
K_{y}^{1-\alpha} \gamma^{\beta}=\lambda \\
\frac{K_{y}^{\alpha} \gamma^{1-\beta} \sigma}{\gamma(\sigma-1)+1}=\tau
\end{array}\right.
$$

where $\lambda \equiv \frac{\alpha A B^{\beta} \rho^{\beta \theta} \theta^{\beta \theta} L^{1-\alpha-\beta}}{r(1-\rho)^{\beta \theta} \eta^{\beta \theta}}$, and $\tau \equiv \frac{r}{A \rho^{\beta \theta} \theta^{\beta \theta} \eta^{1-\beta \theta}(1-\rho)^{1-\beta \theta} B^{\beta} L^{1-\alpha-\beta}}$. These 
two equations can be further reduced to:

$K_{y}=\lambda \tau \frac{\gamma(\sigma-1)+1}{\gamma \sigma}$

$[\gamma(\sigma-1)+1] \gamma^{\frac{\alpha+\beta-1}{1-\alpha}}-\frac{\frac{\alpha}{1-\alpha}}{\tau} \sigma=0$

Equation (22) implicitly defines oil self-sufficiency (or equivalently oil import dependency, $1-\gamma)$ as a non-linear function of the price ratio $(\sigma)$. By totally differentiating Equation (22), we can obtain the first order derivative of oil self-sufficiency $(\gamma)$ with respect to the price ratio $(\sigma)$, as follows:

$\frac{d \gamma}{d \sigma}=-\frac{(1-\alpha) \gamma^{2}}{(\beta \sigma+1-\alpha-\beta) \gamma+\alpha+\beta-1}$

We can also approximate Equation (22) using the first order Taylor expansion at $\gamma=1$, and solve the subsequent linear equation to obtain an approximate steady state value of oil self-sufficiency as follows:

$\gamma=1-\frac{(1-\alpha)\left(\tau-\lambda \frac{\alpha}{1-\alpha}\right) \sigma}{\tau(\sigma \beta+\alpha-1)}$

To solve Equation (23), we first let $g(\gamma)=(\beta \sigma+1-\alpha-\beta) \gamma+\alpha+\beta-$ $1, \gamma \in[0,1]$. Note that since $0<\alpha<1,0<\alpha+\beta<1$, and $\sigma>0, g(\gamma)$ is a monotonically increasing function of $\gamma, g(0)=\alpha+\beta-1<0$ and $g(1)=$ $\beta \sigma>0$. Therefore, if $\gamma<\frac{1-\alpha-\beta}{\beta \sigma+1-\alpha-\beta}, g(\gamma)<0$, then subsequently $d \gamma / d \sigma>0$. If $\gamma=\frac{1-\alpha-\beta}{\beta \sigma+1-\alpha-\beta}, g(\gamma)=0$, then subsequently $d \gamma / d \sigma$ is not defined. If $\gamma>\frac{1-\alpha-\beta}{\beta \sigma+1-\alpha-\beta}, g(\gamma)>0$, then subsequently $d \gamma / d \sigma<0$. Therefore the sign of impact of price distortion ( $\tilde{\sigma})$ on oil self-sufficiency (or equivalently oil import dependency) is not uniform. Summarizing this finding, we arrive at the following propositions: 
Proposition 1: When the steady state economy is at a low self-sufficiency rate (high oil import dependency rate), $\gamma<\frac{1-\alpha-\beta}{\beta \sigma+1-\alpha-\beta}$ ) with upward price distortion or at a high self-sufficiency rate (low oil import dependency rate), $\gamma>\frac{1-\alpha-\beta}{\beta \sigma+1-\alpha-\beta}$ ) with downward price distortion, an increase in oil price distortion $(\tilde{\sigma})$ leads to an increase in the oil self-sufficiency rate (reduction in oil import dependency). In contrast, at a low, self-sufficiency rate with downward price distortion, or at a high, self-sufficiency rate with upward price distortion, an increase in the distortion results in decreasing self-sufficiency (increase in oil import dependency).

From Equations (2), (20), and (21), we can resolve the steady state output, as follows:

$Y=N \frac{[\gamma(\sigma-1)+1]^{2}}{\gamma^{\alpha+\beta} \sigma^{2}}$

where $N \equiv A L^{1-\alpha-\beta} \lambda^{\alpha} \tau^{\alpha} \frac{B^{\beta} \rho^{\beta \theta} \theta^{\beta \theta}}{(1-\rho)^{\beta \theta} \eta^{\beta \theta}} ; \gamma=\gamma(\sigma) ; \gamma \in[0,1] ; \sigma>0$. Differentiate Equation (25) with respect to $\sigma$, we obtain the following equation:

$\frac{d Y}{d \sigma}=N[\gamma(\sigma-1)+1] \gamma^{-\alpha-\beta}\left[-(1-\alpha) \gamma \frac{(2-\alpha-\beta)(\sigma-1) \gamma-\alpha-\beta}{(\beta \sigma+1-\alpha-\beta) \gamma+\alpha+\beta-1}+\frac{2(\gamma-1)}{\sigma^{3}}\right]$

Note in Equation (26), the sign $d Y / d \sigma$ depends on the two terms, $(2-\alpha-$ $\beta)(\sigma-1) \gamma-\alpha-\beta$ and $(\beta \sigma+1-\alpha-\beta) \gamma+\alpha+\beta-1$. Let $\hat{g}(\gamma, \sigma)=$ $(2-\alpha-\beta)(\sigma-1) \gamma-\alpha-\beta$ and $\tilde{g}(\gamma, \sigma)=(\beta \sigma+1-\alpha-\beta) \gamma+\alpha+\beta-$ 1. Observe that $\tilde{g}(\gamma, \sigma)$ is a monotonically increasing function of $\gamma$, with $\tilde{g}(0, \sigma(0))=\alpha+\beta-1<0$ and $\tilde{g}(1, \sigma(1))=\beta \sigma(1)=0$ where $\sigma(0)$ and $\sigma(1)$ denote the associated $\sigma$ when $\gamma$ is equal to 0 and 1 respectively and from Equation (24) $\sigma(1)=0$. Therefore $\tilde{g}(\gamma, \sigma) \leq 0$. 
As for the sign $\hat{g}(\gamma, \sigma)$, if $0<\sigma \leq 1, \hat{g}(\gamma, \sigma) \leq 0$. If $\sigma>1, \tilde{g}(\gamma, \sigma)$ is a monotonically increasing function of $\gamma$, and $-\alpha-\beta \leq \hat{g}(\gamma, \sigma) \leq$ $(2-\alpha-\beta)(\sigma-1)-\alpha-\beta$. Thus if $1<\sigma \leq \frac{2}{2-\alpha-\beta}, \hat{g}(\gamma, \sigma) \leq 0$. If $\sigma>\frac{2}{2-\alpha-\beta},(2-\alpha-\beta)(\sigma-1)-\alpha-\beta>0$, and hence $\hat{g}(\gamma, \sigma)$ can be either negative or positive. Given that $\sigma>\frac{2}{2-\alpha-\beta}$, we can further find that:

$$
\left\{\begin{array}{l}
\hat{g}(\gamma, \sigma) \leq 0, \text { if } \sigma>\frac{2}{2-\alpha-\beta} \text { and } \gamma \leq \frac{\alpha+\beta}{(2-\alpha-\beta)(\sigma-1)} \\
\hat{g}(\gamma, \sigma)>0, \text { if } \sigma>\frac{2}{2-\alpha-\beta} \text { and } \gamma>\frac{\alpha+\beta}{(2-\alpha-\beta)(\sigma-1)}
\end{array}\right.
$$

Summarizing the above discussion, we can characterize the conditions under which the fuel price distortion affects the steady state output, as follows:

Proposition 2: With downward price distortion $(0<\sigma \leq 1)$, price distortion affects the steady state output $\left(\frac{d Y}{d \widetilde{\sigma}}>0\right)$; With low upward price distortion $\left(1<\sigma \leq \frac{2}{2-\alpha-\beta}\right)$ or high price distortion $\left(\sigma>\frac{2}{2-\alpha-\beta}\right)$ and the oil self-sufficiency rate not too high $\left(\gamma \leq \frac{\alpha+\beta}{(2-\alpha-\beta)(\sigma-1)}\right)$, price distortion negatively affects the steady state output $\left(\frac{d Y}{d \widetilde{\sigma}}<0\right)$; With high upward price distortion $\left(\sigma>\frac{2}{2-\alpha-\beta}\right)$ and a high oil self-sufficiency rate (namely $\gamma>$ $\left.\frac{\alpha+\beta}{(2-\alpha-\beta)(\sigma-1)}\right)$, the impact of the distortion is unclear.

\section{Empirical estimations}

In Section 3, we investigate the impact of oil price distortion in a twosector growth model, where we show that fuel price distortion affects the domestic economy (Proposition 2). We now turn to an empirical exercise, using time series data to investigate the impact of gasoline price distortion in 
China.

\subsection{Empirical specification}

Equations (9), (11) and (12) define the optimal level of capital stock in the oil extraction as a function of its one period lag, labour, capital stock in the final goods sector, real interest rate, oil reserve, and oil dependency, as follows:

$$
K_{x t}=f\left(K_{x t-1}, S_{t}, L_{t}, K_{y t}, \gamma_{t}, \sigma_{t}, r_{t}, S_{t-1}, L_{t-1}, K_{y t-1}, \gamma_{t-1}, \sigma_{t-1}, r_{t-1}\right)
$$

where $f(\cdot)$ denotes the associated functional form derived from Equations (9), (10) and (11). By plugging Equation (27) into Equation (7) and using the fact that domestic production of oil is equal to domestic demand minus oil imports, we obtain the following equation:

$$
O_{t}=\frac{1}{\gamma_{t}} S_{t} f\left(K_{x t-1}, S_{t}, L_{t}, K_{y t}, \gamma_{t}, \sigma_{t}, r_{t}, S_{t-1}, L_{t-1}, K_{y t-1}, \gamma_{t-1}, \sigma_{t-1}, r_{t-1}\right)^{\eta}
$$

By plugging Equation (4) into Equation (28) we then find the demand for oil $\left(O_{t}\right)$ as:

$$
O_{t}=\tilde{f}\left(K_{x t-1}, S_{t}, L_{t}, K_{y t}, \gamma_{t}, \sigma_{t}, S_{t-1}, L_{t-1}, K_{y t-1}, \gamma_{t-1}, \sigma_{t-1}\right)
$$

where $\tilde{f}(\cdot)$ denotes the associated functional form. From Equations (29) and (6), we can eliminate $\gamma_{t}$ to obtain the oil demand as follows:

$$
O_{t}=\hat{f}\left(K_{x t-1}, S_{t}, L_{t}, K_{y t}, p_{t}, \sigma_{t}, S_{t-1}, L_{t-1}, K_{y t-1}, \gamma_{t-1}, \sigma_{t-1}\right)
$$

Equation (30) can then be plugged into Equation (2) to obtain the following equation:

$$
Y_{t}=A L_{t}^{1-\alpha-\beta} K_{y t}^{\alpha} \hat{f}\left(K_{x t-1}, S_{t}, L_{t}, K_{y t}, p_{t}, \sigma_{t}, S_{t-1}, L_{t-1}, K_{y t-1}, \gamma_{t-1}, \sigma_{t-1}\right)^{\beta}
$$


We then use the following logarithm linear specification to operationalize Equation (31):

$$
\ln \left(Y_{t}\right)=\phi \ln \left(Y_{t-1}\right)+\lambda_{0}+\lambda_{1} t+\boldsymbol{\theta}^{\prime} \mathbf{Z}_{t}+u_{t}
$$

where $\lambda_{0}, \lambda_{1}, \phi$, and $\boldsymbol{\theta}$ are short-run parameters, with the long-run parameters being $\lambda_{0} /(1-\phi), \lambda_{1} /(1-\phi)$, and $\boldsymbol{\theta} /(1-\phi)$, and $\boldsymbol{Z}_{t}=\left(L_{t} K_{y t} 1-\gamma_{t-1} \sigma_{t} p_{t} \sigma_{t} \times p_{t}\right)^{\prime}$, and $u_{t}$ is an i.i.d. error term. We use $Y_{t-1}$ to capture the impact of lagged variables, such as $L_{t-1}$, in Equation (31), and $\lambda_{0}+\lambda_{1} t+u_{t}$ to capture the rest factors, such as $S_{t}$ and $A$. In vector $\mathbf{Z}_{\boldsymbol{t}}$ we also interact the distortion with oil import price to capture the possible interaction effect between them. Note that Equation (32) is an autoregressive, distributed lag model (ARDL(1,0)), and we can generalize it by allowing for lags in $\boldsymbol{Z}_{t}$ and longer lags in $Y_{t}$, as follows:

$$
\phi(L) \ln \left(Y_{t}\right)=\lambda_{0}+\lambda_{1} t+\boldsymbol{\theta}^{\prime}(L) \boldsymbol{Z}_{t}+u_{t}
$$

where $\phi(L)=1-\sum_{j=1}^{m} \phi_{j} L^{j}$, and $\boldsymbol{\theta}(L)=\sum_{j=1}^{n} \boldsymbol{\theta}_{j} L^{j}$, and $m$ and $n$ denote lag length. Since our data are time series, it is not surprising that $\mathbf{Z s}$ can be nonstationary. Pesaran and Shin (1999) show that the ordinary, least square estimator of the short-run parameters and the corresponding long-run parameter estimates are consistent even if the regressors $\left(\boldsymbol{Z}_{t}\right)$ are $\mathrm{I}(1)$.

It can also be argued that $Z_{t}$ can be endogenous, namely $E\left(u_{t} \mid Z_{t}\right) \neq 0$. For example, on the one hand the oil imports positively contribute to domestic economic growth, while on the other hand, as the economy grows, it may become more and more dependent on oil imports, namely a higher level of $Y$ leads to a higher level of $1-\gamma$. This possible endogeneity can be controlled by including a number of leads and lags of regressors in differences, which absorbs the correlation between regressors and the error term (Stock and 
Watson, 1993). Therefore, we augment Equation (32b) by including the leads and lags of differenced $Z$ and re-write the right hand side variables, as follows:

$$
\Delta \ln \left(Y_{t}\right)=\lambda_{0}+\lambda_{1} t+\phi^{*}(L) \ln \left(Y_{t}\right)+\boldsymbol{\theta}^{\prime} \boldsymbol{Z}_{t}+\sum_{j=-q}^{q} \Delta \boldsymbol{Z}_{t-j}+u_{t}
$$

where $\phi^{*}(L)=\sum_{j=1}^{p} \phi_{j} L^{j}-L, \Delta$ denotes the difference operator (namely $\Delta=$ $1-L$ ), and $q$ denotes the length of lags. Note that the summation in Equation (33) is made from $-q$ to $q$, and thus leads of differenced $\mathbf{Z}$ are included as well.

\subsection{Variable construction and data}

The dataset is a monthly time series from 2005M1 to 2012M12 in China ${ }^{2}$. Data was obtained from the CEIC database, which collects data from different sources. We used two series to measure the output $(y)^{3}$. The first one is the industrial production index, which is calculated from a series (percentage change of industrial production index over the corresponding month of the previous year) sourced from the International Monetary Fund (IMF), assuming year 1993 is 100 . The other is industrial sales in billion Chinese yuan sourced from the National Bureau of Statistics (NBS). We used the producer price index for industrial products, sourced from NBS with a base year of 1997, to deflate the industrial sales. Labour $(L)$ is also sourced from NBS, and is measured as the number of employees in industrial enterprises with the unit being a thousand persons. The labour series has missing values replaced by an interpolation.

The capital ( $K_{y}$, in billion yuan) is constructed from fixed asset investment. First, we calculated the monthly increment of fixed asset investment in

\footnotetext{
${ }^{2}$ This sample period is selected based on data availability.

${ }^{3}$ Due to data unavailability, we do not use GDP as a dependent variable.
} 
secondary industry from year-to-date fixed asset investment data, and deflated it using the fixed asset price index with a base year of 2003. Second, we assumed a monthly capital depreciation rate of $0.4 \%$, which translates to a 4.9\% per annum depreciate rate, and take 2005M1 fixed asset investment as the initial capital stock. The capital stock in subsequent periods is then calculated as: $K_{y t}=I_{t}+(1-0.004) \times K_{y t-1}$, where $I_{t}$ denotes newly increased fixed asset investment in period $t$ and $K_{y 0}=I_{0}$.

The oil dependency $(1-\gamma)$ is measured as the share of oil imports in domestic oil consumption, and is constructed as follows. First, we extracted the imports and exports of crude oil (in million US dollars) and the import and export prices (in US dollars per ton), sourced from General Administration of Customs from the CEIC database. From the value and price of imports and exports, we then calculate the quantity of exports and imports. Second, we extracted the domestic production of crude oil, sourced from NBS. The oil dependency ratio is then calculated as: $1-\gamma=Q_{\text {imports }} /\left(Q_{\text {imports }}+Q_{\text {production }}-\right.$

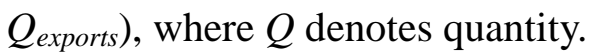

The crude oil import price (US dollar per ton) is sourced from General Administration of Customs. We converted the US dollar denoted price into Chinese yuan by using the period average of the official nominal exchange rate sourced from the IMF, and then deflated the import price by the producer price index for industrial products. The measures of oil price distortion are constructed as discussed in Section 2.

Since the data are monthly time series, it is not surprising that they exhibit seasonality. We thus adjusted the data series by using the X-12-ARIMA 
Seasonal Adjustment Program to eliminate the influence of seasonal fluctuation $^{4}$. The X-12-ARIMA is a standard approach used by the US Census Bureau for seasonal adjustment of time series data.

\subsection{Unit root tests}

We first carried out unit root tests to check the stationarity of the time series. Table 1 reports the results, where both the Augmented Dickey-Fuller (ADF) unit root test (Dickey and Fuller, 1979) and Phillips-Perron (PP) unit root test (Phillips and Perron, 1988) are used. Not surprisingly, it can be observed that some variables are I(1), while others are I(0). The capital stock and oil dependency ratio are both $\mathrm{I}(0)$, where the null hypothesis of unit root is rejected at the $5 \%$ level.

For the measure of domestic oil price distortion, since Figure 1 suggests that there exists a structural break, we carried out the Zivot and Andrews (1992) unit root test that allows for a structural break ${ }^{5}$. Although results in Table 1 indicate that the measure is I(1), the Zivot and Andrews test suggests I(0), with the test statistic being -5.57 , significant at the $5 \%$ level.

The industrial production index is I(1) in that the test statistic for level variable is insignificant while the test statistic for first differenced variables is significant at the $1 \%$ level. Similarly the labour series is I(1). Industrial sales are also considered to be I(1) at the $1 \%$ level, since the test statistics for the PP and ADF with time trend for level variable are only significant at the 5 and

\footnotetext{
${ }^{4}$ Details of the X-12-ARIMA can be found at http://www.census.gov/srd/www/x12a/.

${ }^{5}$ We utilized a program in Stata 13, written by Christopher F. Baum from Boston College, to implement this test. More details of the test can be found in Salim and Bloch Salim R, Bloch H, 2009. Expenditures on Business R\&D and Trade Performance in Australia: Is there a Link? Applied Economics. 41, 351-361.
} 
$10 \%$ levels respectively, and the test statistics for first differenced variable are significant at the $1 \%$ level. Given that variables are a mixture of I(1) and I(0), ARDL modelling is an appropriate approach as it can be applied when variables are of a different order of integration, considered the main advantage of ARDL modelling (Pesaran and Pesaran, 1997).

<Table 1 about here >

\subsection{Regression results}

To estimate Equation (33), we have two measures of industrial output (industrial sales and industrial production index) and two measures of domestic fuel price distortions ${ }^{6}$. In the following, we describe the empirical exercise using industrial sales as the measure of industrial output and the absolute percentage deviation of the China gasoline price from the US gasoline price $(\tilde{\sigma})$ as a measure of oil price distortions, and the rest regressions will follow the same specification. The first step in the exercise is to determine the length of lags. We used the Schwartz's Bayesian Information Criteria (BIC) to determine lag length, and chose the length of lags that yield a minimal BIC. The BIC suggests an optimal lag length of one for both the dependent and explanatory variables in Equation (33).

Table 2 reports the regression results, where the left panel is the estimated results of short-run coefficients, as in Equation (33), and the right panel is the associated long-run coefficients. After the regression, we also carried out a set of diagnostic tests. The Breusch-Godfrey test for serial correlation found no evidence of first, second, third, fourth, or fifth order autocorrelation at the $1 \%$

\footnotetext{
${ }^{6}$ The measure of downward price distortion $\left(\tilde{\sigma}^{-}=\max \{1-\sigma, 0\}\right)$ is not used due to lack of variations.
} 
significance level. An LM test for autoregressive conditional heteroskedasticity (ARCH) also failed to reject the null hypothesis of no ARCH effects at the $1 \%$ level. The Breusch-Pagan/Cook-Weisberg test for heteroskedasticity obtained a test statistic of 47.72 with a p-value of 0.006 , suggesting existence of heteroskedasticity. Therefore, we report the robust standard errors in the regressions. We also examined the stationarity of the residual by conducting both $\mathrm{ADF}$ and $\mathrm{PP}$ tests, which both reject the null hypothesis of unit root at the $1 \%$ level. Figure 2 presents the plots of the cumulative sum of recursive residuals (CUSUM) and the squared CUSUM (CUSUMSQ) tests for parameter stability. It suggests an absence of coefficient instability as both statistics fall approximately inside the $5 \%$ confidence interval in the plots. Therefore the regression is appropriate.

$<$ Table 2 about here $>$

$<$ Figure 2 about here $>$

The long-run (steady state) coefficients in Table 2 are computed as shortrun coefficients divided by the negative of the coefficient of $\ln y_{t-1}$, and the associated standard errors are computed using the delta method. For example, let $\varphi$ and $\theta_{l}$ (one element of $\boldsymbol{\theta}$ in Equation 33) denote the long-run and shortrun coefficients of labour $\left(\ln l_{t}\right)$ respectively, and $\phi_{y}$ denote the coefficient of lagged industrial output $\left(\ln y_{t-1}\right)$. Then $\varphi=-\theta_{l} / \phi_{y}$. To obtain the associated standard error, we first linearize $\varphi$ by the first order Taylor approximation at the point estimates of $\theta_{l}$ and $\phi_{y}$, namely $\varphi \cong-\hat{\theta}_{l} / \hat{\phi}_{y}-\left(\theta_{l}-\hat{\theta}_{l}\right) / \hat{\phi}_{y}+$ $\hat{\theta}_{l}\left(\phi_{y}-\hat{\phi}_{y}\right) / \hat{\phi}_{y}^{2}$, where the hat denotes point estimate. Then $\widehat{\operatorname{var}(\varphi)}=$ 
$\left.\operatorname{var}\left(\theta_{l}\right) / \hat{\phi}_{y}^{2}+\hat{\theta}_{l}^{2} \operatorname{var(\phi _{y})} / \hat{\phi}_{y}^{4}-2 \hat{\theta}_{l} \operatorname{cov} \widehat{\left(\theta_{l},\right.} \phi_{y}\right) / \hat{\phi}_{y}^{3}$, and $s e=\sqrt{\sqrt[\operatorname{var}(\varphi)]{ }}$, where var, cov and se denote variance, covariance and standard error respectively.

In Table 2, the significantly negative coefficient of lagged industrial sales suggests that industrial sales growth rate decreases as it grows bigger ${ }^{7}$. This regressive development is consistent with the finding of Sheng and Shi (2013) that economic growth across countries converges unconditionally. Not surprisingly, labour and capital positively contribute to industrial growth, and the coefficient of time is positive and significant at the $10 \%$ level, confirming the role of technological progress. Oil dependency $\left(1-\gamma_{t}\right)$ appears not to significantly affect industrial growth in the short run.

Regarding the impacts of oil import price and fuel price distortion, the estimated coefficients of both oil price distortion and oil import price are significantly negative, and the coefficient of their interaction term is significantly positive. The significant estimate suggests that both oil import price and price distortion play important roles in the economy. We then differentiate the estimated equation with respect to the oil import price and price distortion, respectively, to obtain their marginal impacts, as follows:

$$
\begin{aligned}
& \frac{\partial \mathrm{E}\left[\Delta \ln y_{\mathrm{t}}\right]}{\partial \ln p_{\mathrm{t}}}=-0.0766+0.2403 \times \tilde{\sigma} \\
& \frac{\partial \mathrm{E}\left[\Delta \ln \mathrm{y}_{\mathrm{t}}\right]}{\partial \ln \tilde{\sigma}}=-1.9335+0.2403 \times \ln _{\mathrm{t}}
\end{aligned}
$$

Therefore, the marginal impact of oil import price depends on the level of

\footnotetext{
${ }^{7}$ Note $\Delta \ln \left(y_{t}\right)$ is approximately growth rate of industrial output.
} 
price distortion and at the same time the marginal impact of fuel price distortion also depends on the level of oil import price.

In the long run (steady state), the coefficients of all the variables, except oil dependency, are significant and maintain the same sign as in the short run. Regarding the long run impacts of oil import price and price distortion, similar to before, we can obtain the marginal impacts as below:

$$
\begin{aligned}
& \frac{\partial \mathrm{E}[\ln y]}{\partial \ln \mathrm{p}}=-.0721+0.2263 \times \tilde{\sigma} \\
& \frac{\partial \mathrm{E}[\ln y]}{\partial \tilde{\sigma}}=-1.821+0.2263 \times \ln \mathrm{p}
\end{aligned}
$$

\subsection{Robustness}

The previous exercise found that oil price distortion exerts a significant impact on industrial production over both the short and the long term. However, is this finding robust enough to use as an alternative measure of industrial production? In this section, we explore this using an industrial production index as a measure of output.

Due to the way the original data are reported, namely, the original series is the percentage change in the industrial production index over the corresponding month of the previous year, we have to assume that in each month of 1993 the production index is 100 in order to calculate the index from 2005M1 to 2012M12. Owing to this assumption, results in Table 3 serve only as a comparison to those in Table 2. Compared with Table 2, the signs of coefficients of distortion, oil import price and their interaction term, continue to hold in both the short and the long run.

The coefficients of lagged industrial production index and capital have the 
same sign as those of Table 2, while their magnitude is different. The coefficient of labour now becomes insignificant at the $1 \%$ level. Therefore, even though we observe some variations in the coefficient estimate between Tables 2 and 3, the impact of oil price distortion appears to be robust to different measures of industrial production.

$<$ Table 3 about here $>$

As discussed in Section 2, we also constructed measures of upward and downward distortions, in order to accommodate for the possibility that the impact is asymmetric. We re-estimated Equation (33) using the upward distortion, where the length of lag is one. Table 4 reports the results. Comparing the estimated coefficients of oil import price, price distortion and their interaction term with those of Table 2, the regression exhibits little variation. The coefficients of the other variables are also approximately in line with those of Table 2. Hence, the findings are robust to alternative measures of price distortion.

$<$ Table 4 about here $>$

Figure 1 suggests a structural break for oil price distortion exists in 2009M1. So, in the above exercise, we also included a dummy variable that takes a value of one in the time after 2009M1 into the regression. The estimation finds that the coefficient of the dummy variable is insignificant at the $1 \%$ level, and there is only little variation in the coefficients of the other variables. Thus, it appears this structural break does not significantly affect the regression results. 


\section{Concluding remarks}

This paper explores the impact of oil price distortion on domestic economy both theoretically in a two-sector growth model, and empirically in China. In the theoretical model, we show that price distortion can negatively affect the steady state output. Empirically, using a specification derived from the theoretical model, we applied the ARDL modeling technique to a monthly time series dataset in China from 2005M1 to 2012M12, and found that oil price distortion can do harm to industrial growth in the short term, and furthermore, this negative impact persists into the long term. The impact of oil price distortion appears to be robust to different measures of industrial production.

This finding, that price distortion, which occurs mainly due to price regulation, can harm economic growth, contradicts a common argument for energy price regulation, namely that price regulation can shield the domestic economy from negative oil price shocks in the world market.

This study lends its support to energy price deregulation, namely that it is justifiable to remove policies and interventions, such as subsidies, which may distort domestic energy prices, on the grounds that they hurt the domestic economy. A market oriented, energy price regime may improve the resilience of the domestic economy to global, oil price shocks. Although removal of subsidies is sensitive and difficult, a gradual approach is still possible, as China has demonstrated in the past.

However, even in China, the removal of regulations from prices is challenging, as it needs coordination and cooperation within the government 
and support of the public and other key stakeholders. What should be done immediately is to build consensus about removal of energy price regulation among various stakeholders. Also, the government could move forward a little bit by reducing the frequency of price adjustments, replacing regulatory prices with benchmark prices, and allowing increased variation from benchmark prices. 
Table 1 Unit Root Tests

\begin{tabular}{|c|c|c|c|c|c|c|c|c|c|}
\hline \multirow[b]{3}{*}{ Variables } & \multicolumn{4}{|c|}{ Levels } & \multicolumn{4}{|c|}{ First Difference } & \multirow[b]{3}{*}{ Results } \\
\hline & \multicolumn{2}{|c|}{$\mathrm{ADF}$} & \multicolumn{2}{|r|}{$\mathrm{PP}$} & \multicolumn{2}{|c|}{$\mathrm{ADF}$} & \multicolumn{2}{|r|}{$\mathrm{PP}$} & \\
\hline & Constant & $\begin{array}{l}\text { Constant + } \\
\text { Trend }\end{array}$ & Constant & $\begin{array}{l}\text { Constant + } \\
\text { Trend }\end{array}$ & Constant & $\begin{array}{l}\text { Constant + } \\
\text { Trend }\end{array}$ & Constant & $\begin{array}{l}\text { Constant + } \\
\text { Trend }\end{array}$ & \\
\hline Industrial sales $(\ln Y)$ & -0.98 & -3.72 & -1.16 & -3.38 & -17.15 & -17.24 & -18.15 & -18.63 & $\mathrm{I}(1)$ \\
\hline Industrial production index $(\ln Y)$ & -1.41 & -2.14 & -1.62 & -1.95 & -9.37 & -9.49 & -9.44 & -9.62 & $\mathrm{I}(1)$ \\
\hline Labour $(\ln L)$ & -1.18 & -3.05 & -1.12 & -2.72 & -13.33 & -13.3 & -14.04 & -14.04 & $\mathrm{I}(1)$ \\
\hline Capital $(\ln K)$ & -19.71 & -12.91 & -12.59 & -12.7 & -1.91 & -4 & -1.48 & -4.07 & $\mathrm{I}(0)$ \\
\hline Oil dependency $(1-\gamma)$ & -2.88 & -10.03 & -2.22 & -10.07 & -20.75 & -20.65 & -24.99 & -25 & $\mathrm{I}(0)$ \\
\hline Oil import price $(\ln p)$ & -1.77 & -1.82 & -2.41 & -2.53 & -5.66 & -5.63 & -5.67 & -5.64 & $\mathrm{I}(1)$ \\
\hline Fuel price distortion $(\tilde{\sigma})$ & -2.6 & -2.81 & -2.49 & -2.75 & -9.09 & -9.05 & -9.15 & -9.1 & $\mathrm{I}(1)$ \\
\hline
\end{tabular}

Note: The null hypothesis is that the series contain a unit root. 
Table 2 Regression Results with Industrial Sales

\begin{tabular}{|c|c|c|c|c|c|c|}
\hline & \multicolumn{3}{|c|}{ Short-run coefficients } & \multicolumn{3}{|c|}{ Long-run coefficients } \\
\hline & Coef. & Std. Err. & $\mathrm{t}$ & Coef. & Std. Err. & $\mathrm{t}$ \\
\hline $\ln y_{t-1}$ & -1.0618 & $(0.1950)$ & -5.45 & & & \\
\hline $\ln l$ & 0.6382 & $(0.1934)$ & 3.3 & 0.6010 & $(0.1454)$ & 4.13 \\
\hline $\ln k$ & 0.3327 & $(0.0942)$ & 3.53 & 0.3133 & $(0.0785)$ & 3.99 \\
\hline $1-\gamma$ & -0.1041 & $(0.4121)$ & -0.25 & -0.0980 & $(0.3961)$ & -0.25 \\
\hline$t$ & 0.0037 & (0.0019) & 1.95 & 0.0035 & $(0.0016)$ & 2.2 \\
\hline$\tilde{\sigma}$ & -1.9335 & $(0.5606)$ & -3.45 & -1.8210 & $(0.5483)$ & -3.32 \\
\hline $\ln p$ & -0.0766 & $(0.0351)$ & -2.18 & -0.0721 & $(0.0312)$ & -2.31 \\
\hline $\ln p \times \tilde{\sigma}$ & 0.2403 & $(0.0714)$ & 3.37 & 0.2263 & $(0.0706)$ & 3.2 \\
\hline constant & -1.2494 & (1.5275) & -0.82 & & & \\
\hline Number of obs & 92 & & & & & \\
\hline $\mathrm{F}$ & 2.76 & & & & & \\
\hline Adjusted R2 & 0.6 & & & & & \\
\hline
\end{tabular}

Note: the dependent variable is $\Delta \ln (\mathrm{yt})$; the estimated coefficients of $\Delta \mathrm{Zt}$ are not reported to save space; the length of optimal lead and lag is one, namely one lag and one lead. 
Table 3 Regression Results with Industrial Production Index

\begin{tabular}{lrlrlllr}
\hline & \multicolumn{3}{c}{ Short-run coefficients } & \multicolumn{3}{c}{ Long-run coefficients } \\
\cline { 2 - 8 } & Coef. & \multicolumn{1}{c}{ Std. Err. } & \multicolumn{1}{c}{ Coef. } & \multicolumn{1}{c}{ Std. Err. } & $\mathrm{t}$ \\
\hline $\ln y_{t-1}$ & -0.3357 & $(0.0975)$ & -3.44 & & & \\
$\ln l_{t}$ & 0.0772 & $(0.0525)$ & 1.47 & 0.2299 & $(0.1441)$ & 1.60 \\
$\ln k_{t}$ & 0.0887 & $(0.0408)$ & 2.17 & 0.2643 & $(0.0961)$ & 2.75 \\
$1-\gamma_{t-1}$ & -0.0934 & $(0.0971)$ & -0.96 & -0.2782 & $(0.3049)$ & -0.91 \\
$t$ & 0.0011 & $(0.0007)$ & 1.6 & 0.0034 & $(0.0018)$ & 1.88 \\
$\tilde{\sigma}$ & -0.3920 & $(0.1476)$ & -2.66 & -1.1678 & $(0.5272)$ & -2.22 \\
$\ln p_{t}$ & -0.0058 & $(0.0091)$ & -0.64 & -0.0172 & $(0.0283)$ & -0.61 \\
$\ln p \times \tilde{\sigma}$ & 0.0493 & $(0.0187)$ & 2.63 & 0.1468 & $(0.0673)$ & 2.18 \\
constant & 0.5348 & $(0.5354)$ & 1 & & & \\
Number of obs & 92 & & & & & \\
F & 5.83 & & & & & \\
Adjusted R2 & 0.68 & & & & & \\
\hline
\end{tabular}

Note: the dependent variable is $\Delta \ln (\mathrm{yt})$; the estimated coefficients of $\Delta \mathrm{Zt}$ are not reported to save space. 
Table 4 Regression Results with Alternative Measure of Distortion

\begin{tabular}{lrlrlrlr}
\hline & \multicolumn{3}{c}{ Short-run coefficients } & \multicolumn{3}{c}{ Long-run coefficients } \\
\cline { 2 - 8 } & Coef. & \multicolumn{3}{c}{ Std. Err. } & \multicolumn{1}{c}{ Coef. } & Std. Err. & \multicolumn{1}{c}{ t } \\
\hline $\ln y_{t-1}$ & -1.0478 & $(0.1796)$ & -5.83 & & & \\
$\ln l_{t}$ & 0.6974 & $(0.1734)$ & 4.02 & 0.6656 & $(0.1393)$ & 4.78 \\
$\ln k_{t}$ & 0.2901 & $(0.0878)$ & 3.3 & 0.2769 & $(0.0748)$ & 3.70 \\
$1-\gamma_{t-1}$ & -0.1133 & $(0.2657)$ & -0.43 & -0.1082 & $(0.2633)$ & -0.41 \\
$t$ & 0.0042 & $(0.0019)$ & 2.25 & 0.0040 & $(0.0016)$ & 2.55 \\
$\tilde{\sigma}$ & -1.9575 & $(0.4267)$ & -4.59 & -1.8682 & $(0.4286)$ & -4.36 \\
$\ln p_{t}$ & -0.0705 & $(0.0392)$ & -1.8 & -0.0673 & $(0.0372)$ & -1.81 \\
$\ln p \times \tilde{\sigma}$ & 0.2423 & $(0.0539)$ & 4.49 & 0.2312 & $(0.0548)$ & 4.22 \\
constant & -1.6680 & $(1.5175)$ & -1.1 & & & \\
Number of obs & 92 & & & & & \\
F & 4.18 & & & & & & \\
Adjusted R2 & 0.63 & & & & & \\
\hline
\end{tabular}

Note: the dependent variable is $\Delta \ln \left(\mathrm{y}_{\mathrm{t}}\right)$, where y is industrial sales; the upward price distortion is defined as $\tilde{\sigma}^{+}=\max \left\{P_{\text {China }} / P_{U S}-1,0\right\}$; the estimated coefficients of $\Delta \mathrm{Zt}$ are not reported to save space. 
Figure 1 The Price Distortion in China

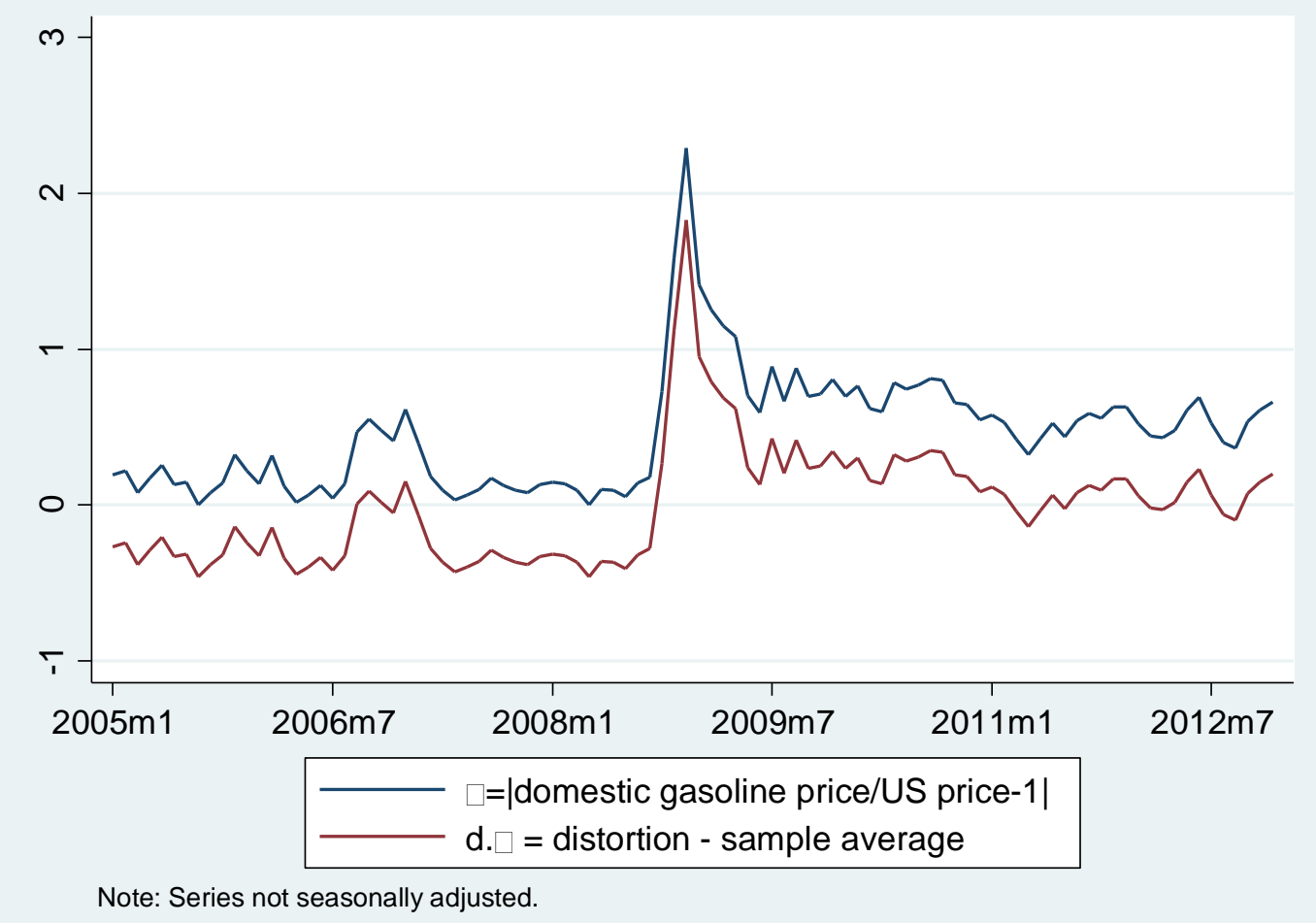

Source: The authors' calculation with data sourced from the CEIC database, EIA, and IMF. 
Figure 2 Plots of CUSUM and CUSUMSQ Tests
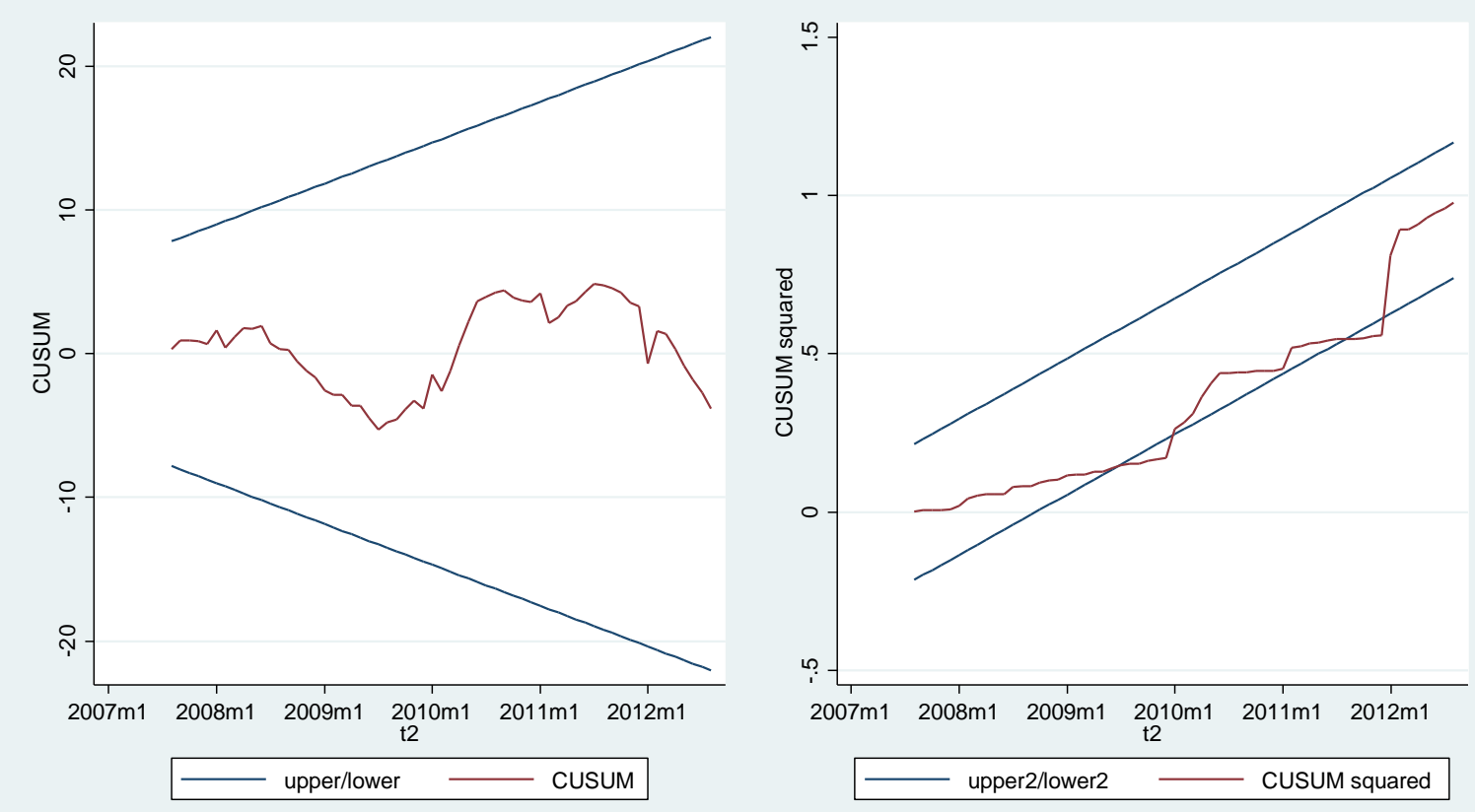


\section{References}

An L, Jin X, Ren X, 2014. Are the macroeconomic effects of oil price shock symmetric?: A FactorAugmented Vector Autoregressive approach. Energy Economics. 45, 217-228.

Barsky R, Kilian L, 2004. Oil and the Macroeconomy Since the 1970s, NBER Working Paper 10855. National Bureau of Economic Research, Cambridge.

Bernanke BS, Markwardt G, Watson MW, 1997. Systematic Monetary Policy and the Effects of Oil Price Shocks. Brookings Papers on Economic Activity. 1, 91-142.

Bhattacharya A, Kojima S, 2010. Estimated Benefits from EMI, in: SHI X, Kimura F (Eds.), Energy Market Integration in the East Asia Summit region: review of initiatives and estimation of beneftis. Economic Research Institute for ASEAN and East Asia, Jakarta, pp. 24-31.

Broadstock DC, Wang R, Zhang D, 2014. Direct and indirect oil shocks and their impacts upon energy related stocks. Economic Systems. 38, 451-467.

China.org.cn, 2013. China adjusts oil price mechanism. http://www.china.org.cn/business/201303/26/content 28365275.htm (Accessed 3 May 2013).

Clark TE, Terry SJ, 2009. Time Var iation in the Inflation Passthrough of Energy Pr ices, Research Working Papers RWP09-06. The Federal Reserve Bank of Kansas City Economic Research Department, Kansas.

Cunado J, Jo S, Perez de Gracia F, 2015. Macroeconomic impacts of oil price shocks in Asian economies. Energy Policy. 86, 867-879.

Darby M, 1982. The price of oil and world inflation and recession. American Economic Review. 72, 738-751.

Dickey DA, Fuller WA, 1979. Distribution of the estimators for autoregressive time series with a unit root. Journal of the American Statistical Association. 74, 427-431.

Du L, He Y, Wei C, 2010. The Relationship between oil price shocks and China's marco-economy: An empirical analysis. Energy Policy. 38, 4142-4151.

Global Subsidies Initiative (GSI) 2011. People's Guideline to Energy Subsidies in In Indonesia. IISD/GSI, Geneva.

Government of China, 2008. State Council Notice on the Implementation of Oil Price and Tax Reform [27/2008]. http://www.gov.cn/zwgk/2008-12/19/content 1182128.htm (Accessed 17 December 2014).

Hamilton J, 1983. Oil and the Macroeconomy Since Wolrd War II. Journal of Political Economy. 91, 921-948.

He Y, Liu Y, Wang J, Xia T, Zhao Y, 2014. Low-carbon-oriented dynamic optimization of residential energy pricing in China. Energy. 66, 610-623.

Huang $Y, 2015$. Is it leagal to increase the fuel tax three times within 45 days. http://finance.people.com.cn/n/2015/0126/c1004-26447107.html (Accessed 18 August 2016).

IEA, 1999. World energy outlook: looking at energy subsidies: getting the price right. IEA, Paris.

IEA, 2010. World Energy Outlook 2010. International Energy Agency, Paris.

IEA, 2015. World Energy Outlook 2015. IEA, Paris.

IMF, 2013. Energy Subsidy Reform: Lessons and Implications. International Monetary Fund (IMF), Washington, D.C.

Jones DW, Leiby PN, Paik IK, 2004. Oil Prices Shocks and the Macroeconomy: What Has Been Learned Since 1996. The Energy Journal. 25, 1-32.

Ju K, Zhou D, Zhou P, Wu J, 2014. Macroeconomic effects of oil price shocks in China: An empirical study based on Hilbert-Huang transform and event study. Applied Energy. 136, 1053-1066.

Kilian L, 2008. A Comparison of the Effects of Exogenous Oil Supply Shocks on Output and Inflation in the G7 Countries. Journal of the European Economic Association. 6, 78-121.

Kilian L, 2014. Oil Price Shocks: Causes and Consequences (February 2014), CEPR Discussion Paper No. DP9823. 
Kojima M, 2012. Oil price risks and pump price adjustments, Policy Research Working Paper 6227. The World Bank.

Lin B, Jiang Z, 2011. Estimates of Energy Subsidies in China and Impact of Energy Subsidy Reform. Energy Economics. 33, 273-283.

Linn J, 2008. Energy Prices and the Adoption of Energy-Saving Technology. The Economic Journal. $118,1986-2012$.

Liu W, Li H, 2011. Improving energy consumption structure: a comprehensive assessment of fossil energy subsidies reform in China. Energy Policy. 39.

Nwachukwu M, Chike H, 2011. Fuel subsidy in Nigeria: fact or fallacy. Energy. 36, 796-801.

Ou B, Zhang X, Wang S, 2012. How does China's macro-economy response to the world crude oil price shock: A structural dynamic factor model approach. Computers \& Industrial Engineering. 63, 634-640.

Ouyang X, Sun C, 2015. Energy savings potential in China's industrial sector: From the perspectives of factor price distortion and allocative inefficiency. Energy Economics. 48, 117-126.

Pesaran MH, Pesaran B, 1997. Working with Microfit 4.0: Interactive Econometric Analysis. Oxford University Press, Oxford.

Pesaran MH, Shin Y, 1999. An autoregressive distributed lag modelling approach to cointegration analysis, In: Strom S, Holly A, Diamond P (Eds), Econometrics and Economic Theory in the 20th Century: The Ragner Frisch Centennial Symposium. Cambridge University Press, Cambridge; 1999.

Phillips PCB, Perron P, 1988. Testing for a unit root in time series regression. Biometrika. 75, 335346.

Salim R, Bloch H, 2009. Expenditures on Business R\&D and Trade Performance in Australia: Is there a Link? Applied Economics. 41, 351-361.

Segal P, 2007. Why Do Oil Price Shocks No Longer Shock?, Oxford Institute for Energy Studies Working Paper WPM 35. Oxford Institute for Energy Studies, Oxford.

Sheng Y, Shi X, 2013. Energy market integration and Equitable Growth Accross Countries. Applied Energy. 104, 319-325.

Stock JH, Watson MW, 1993. A Simple Estimator of Cointegrating Vectors in Higher Order Integrated Systems. Econometrica. 61, 783-820.

Tang W, Wu L, Zhang Z, 2010. Oil Price Shocks and Their short- and long-term effects on the Chinese economy. Energy Economics. 32, s3-14.

Wu L, Li J, Zhang Z, 2013. Inflationary effect of oil-price shocks in an imperfect market: A partial transmission input-output analysis. Journal of Policy Modeling. 35, 354-369.

Wu Y, Shi X, Kimura F, 2012. Energy Market Integration in East Asia: Theories, Electricity Sector and Subsidies. Economic Research Institute for ASEAN and East Asia, Jakarta.

Xin Jing Bao, 2011. Why China's Gasoline Price is More Expensive than the US's, Xin Jing Bao, Beijing.

Zaouali S, 2007. Impact of Higher Oil Prices on the Chinese Economy. OPEC Review. 3, 191-214.

Zhang D, 2008. Oil shock and economic growth in Japan: A nonlinear approach. Energy Economics. 30, 2374-2390.

Zhang D, Broadstock DC, Cao H, 2014. International oil shocks and household consumption in China. Energy Policy. 75, 146-156.

Zivot E, Andrews D, 1992. Further evidence on the great crash, the oil-price shock, and the unitroot hypothesis. Journal of Business and Economic Statistics. 10, 251-270. 